\title{
Comprehension Process Overview
}

\section{André Michaud*}

President of SRP Inc, Canada

\section{Abstract \\ Here is a brief overview of the main features of the comprehension process, stemming from the research of Pavlov, Chauchard and Korzybski.}

Keywords: Korzybski; Chauchard; Pavlov; Neocortex; Verbal Areas; Brain; Conceptual Thinking; Objective Reality; General Semantics

\section{Introduction}

Before intelligence, or should we rather say "the comprehension ability", can be defined, it is mandatory to describe the thinking process. After lengthy experimentation, Pavlov determined that we think in two different modes [1-3].

\section{1- Thinking mode by images association.}

2- Thinking mode by words association.

The thinking mode by images association is a reflection of the circulation of what we name "our awareness" in the set of sequences of memories corresponding to the perceptions of our senses: visual images, tactile sensations, sounds, etc., the complete set being stored in recoverable order of occurrence in various areas of the neocortex [4], each area corresponding to one of our senses. The sequences of events stored in the various neocortex areas are also mutually interconnected in such a way that we can easily access what we can remember of these sensory perceptions for any specific past event.

The set of all symbolic images that we elaborate and that we can have come to mind, and all emotions that we feel must also be included in the thinking mode by images association.

The thinking mode by words association is a manifestation of the circulation of "our awareness" in an infrastructure of links that have been established in our neocortex between the various aspects of our memories as a consequence of the use of the language or languages that we use to think, write and speak about them [5], French, German, Spanish, English, Russian, etc.

We observe the external world as well as the internal world of our emotions with the images thinking mode, but we comprehend and describe it with the verbal thinking mode.

An important aspect of each object, event, chain of events, concept or emotion that we may think about with the thinking mode by images is that it potentially possesses an infinite number of characteristics [6].

Another important aspect of the images thinking mode is that we never need to have perceived the totality of this infinite number of characteristics of an object, event, concept or emotion before we can objectively understand its nature $[7,8]$.

Consequently, for any object, event, concept or emotion that we may think about, there exists a restricted set of characteristics that allows objective understanding of its nature.

The main characteristic of the verbal thinking mode is the generalization ability [9] that it provides us with. This generalization ability is the process by which a bunch of images can be associated in our mind by at least one characteristic. Each word potentially is a generalization.

The word "dog", for example, can cause a person to think about a specific dog, about all dogs that he or she has known, about all he or she knows about dogs, about the owner of a particular dog he or she is afraid of, etc. The degree of generalization carried by a word, in any language whatsoever is always determined by the global context, that is, by reference to the frame of references in which it is used.

\section{Literature Review}

We can now discuss intelligence, that is, the comprehension ability.

The mechanism of comprehension involves the use of two distinct processes.

1- The correlation process [10].

2- The comprehension process [11].

A correlation being a relation perceived between two or more things, the correlation process, allowed only by the generalization ability which is an exclusive characteristic of the interior language, is a neocortex automatic process of memory search by chaining of successive correlations between elements pertaining, to any degree, to the subject being examined, always initiated by a self questioning on this issue and usually resulting in the perception of a coherence in the set of associated elements.

However, the perception of a coherence [12], which is another neocortex automatic process, that is, the impression of "having understood something" following cogitation on this issue does not, as such, guarantee that the subject of our cogitation has been objectively understood. Therefore, another process must be at play in order to orient our thinking towards true objective comprehension, which always is the ultimate goal.

The comprehension process is a method used by the human brain, consisting in exploring and re-exploring a concept until objective understanding of the concept as a whole has been reached.

*Corresponding author: André Michaud, President of SRP Inc, Canada; E-mail: srp2@srpinc.org

Received August 01, 2016; Accepted September 26, 2016; Published October 07, 2016

Citation: Michaud A (2016) Comprehension Process Overview. J Biom Biostat 7 317. doi:10.4172/2155-6180.1000317

Copyright: @ 2016 Michaud A. This is an open-access article distributed under the terms of the Creative Commons Attribution License, which permits unrestricted use, distribution, and reproduction in any medium, provided the original author and source are credited. 
Each new exploration of the same concept, initiated by questions raised by aspects of the concept that still remain unclear, will induce the individual to reconsider, taking into account more newly acquired or newly considered characteristics, which will lead to the perception of new and sharper coherences. The final coherence will ideally enclose the restricted set of objective characteristics that objectively describes the concept being explored.

This presumably final coherence can tentatively be identified by the fact that a series of repeated further re-questioning causing more and more data to be considered does not cause the concept to become clearer. However, an unmistakable telltale that final objective comprehension of any concept has not been reached is the fact that any of its aspects remains unclear or unexplained.

The only means at our disposal to let the comprehension process operate efficiently, is to consciously force ourselves never to be totally certain that we have objectively understood any given, object, concept, etc. [13], which maintains the individual alert to any further information that could cause the concept to become clearer.

\section{Conclusion}

The generalization ability, which is the very foundation of the whole comprehension mechanism, being an exclusive property of language, it follows that the more articulate we verbally become, the more efficiently the comprehension process will operate.

The degree of awakening of intelligence, that is, of the comprehension ability, is therefore directly linked to the degree of mastery of language [14].

At birth, the neocortex areas that will support the verbal thinking mode are not yet physically interconnected with the areas that already support the thinking mode by images. The necessary synaptic connections will be established as the child learns to speak, read and write.

The establishment of the myelin sheets about the dendrites interconnecting the neurons of the verbal areas is genetically delayed in humans, contrary to the rest of the neocortex, so that their physical presence does not hinder the rapid construction of the network of interconnections that will be established during infancy [15]. This is why children so easily learn any language or even many languages during infancy.

In humans, the myelinization of the verbal areas of the neocortex is genetically triggered at the age of about 7 [16], age after which further construction becomes more difficult (requires greater efforts) on account of the physical presence of the newly established myelin sheaths about the existing dendrites in the verbal areas.

So only the first seven years of life are available for easy and rapid synaptic interconnection between the areas supporting verbal thought and the areas supporting thought by images [17]. It is therefore imperative that children become sufficiently verbally articulate in infancy for him or her to easily express his or her thoughts and easily describe what he or she perceives and understands.

Such early mastery will cause further learning after myelinization to remain easy due to children having now become more interested in what reading gives them access to, rather than having to concentrate at the now more difficult task of finishing mastering an imperfect reading skill.

The density of the interconnecting synaptic network that will be physically established between the areas of thought by images and the areas of verbal thought, and that will serve for the rest of the individual's life, is directly dependent on the quality of that early development of the verbal abilities [18].

It must be said, however, for those whose verbal development conditions could have been less than optimal, that the situation seems to be repairable in part, and maybe completely, to the degree that the person concerned is interested and ready to invest the time and effort required.

On their part, IQ tests quite obviously measure the speed with which a person can perceive specific coherences. That speed seems to be in relation with the quality of the language acquired in infancy, but also constantly seems to vary during the lifetime of an individual as a function of the intensity of use of the language areas [19].

A heavy reader, for example, intensely uses the areas supporting verbal thought and will probably see an increase in his or her coherence perception speed. Conversely, if that person stops reading for a period of time, he or she will probably see a decrease in his or her coherence perception speed. Many other factors certainly also have to be taken into account [20].

Since the comprehension process mandatorily involves a permanent questioning process that leads, with time, to the perception of a series of increasingly precise coherences for each object, event, concept or emotion of real life that an individual may think about, tests measuring only the speed with which specific coherences can be perceived by an individual, can in no way give any idea of the degree to which that individual uses the comprehension process [21].

By its very nature, the closeness of a perceived coherence to objective reality can be verified only in relation with the perceived coherences of other persons considering the same object, event, concept or emotion, because there is only one objective reality [22-24].

\section{References}

1. Michaud A (1997) Einstein's Operating System, Chapter-Two Centres of Thought.

2. Chauchard $P(1960)$ Le cerveau et la conscience. Chapter-Les deux niveaux de la pensée p: 119

3. Pickenhein L (1998). I.P. Pawlow, Gesammelte Werke. Ergon Verlag. page 183, Chapter Der bedingte Reflex", and page 391, Chapter "Das zweite Signalsystem.

4. Michaud A (2003) The Neurolinguistic Foundation of Intelligence. Chapter-The Human Brain.

5. Michaud A (2003) The Neurolinguistic Foundation of Intelligence. ChapterStructure of the Verbal Hemisphere.

6. Poincaré $H$ (1905) La valeur de la science. Flammarion pp: 171-187.

7. Korzybski A (1933) Science \& Sanity. The Institute of General Semantics.

8. Michaud A (1997) Einstein's Operating System. Chapter-The Comprehension Process, Defining the Smallest Objective Set.

9. Michaud A (2003) The Neurolinguistic Foundation of Intelligence. ChapterObjects and Their Characteristics.

10. Michaud A (2003) The Neurolinguistic Foundation of Intelligence. ChapterIntelligence.

11. Michaud A (2003) The Neurolinguistic Foundation of Intelligence. Chapter-The Coomprehension Process.

12. Michaud A (1999) Theory of Discrete Attractors. Chapter-Reasoning by Perception of Coherences, Example of Reasoning by Perception of Coherences.

13. Michaud A (1997) Einstein's Operating System. Chapter-Defining the Comprehen-sion Process. 
14. Michaud A (1998) A Future as an Heirloom. Chapter-What is intelligence.

15. Flechsig P (1920) Anatomie des Menschlichen Gehirns und Rückenmarks auf Myelogenetischen Grundlage. Leipzig.

16. Chauchard P (1960) Le cerveau et la conscience. Éditions du Seuil p: 45.

17. Chauchard P (1960) Le cerveau et la conscience. Éditions du Seuil pp: 38-52.

18. Chauchard P (1960) Le cerveau et la conscience. Éditions du Seuil pp: 115.

19. Michaud A (1997) Einstein's Operating System. Chapter-Redefining Intelligence.
20. Michaud A (2003) The Neurolinguistic Foundation of Intelligence. ChapterWhat Does IQ Testing Measure.

21. Michaud A (2003) The Neurolinguistic Foundation of Intelligence. ChapterEarly Childhood.

22. Michaud A (1998) A Future as an Heirloom. Part 2-Perception of Reality.

23. Michaud A (2003) The Neurolinguistic Foundation of Intelligence. ChapterRequestioning.

24. Korzybski A (1933) Science \& Sanity. The Institute of General Semantics. 